\title{
Edgar, um intelectual militante
}

Patrus Ananias de Sousa*

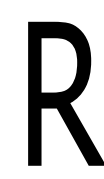

evisitei, com renovadas emoções, a obra do professor Edgar de Godói da Mata-Machado. Reli textos admiráveis escritos ao longo de sua vida fecunda: jornalista, professor, pensador do Direito, ensaísta e militante político. Tradutor primoroso de obras que cobrem um arco que vai do "Diário de um pároco de aldeia", de George Bernanos, a "A filosofia do governo democrático", de Ives Simon, passando por "Arte e poesia" e "Sobre a filosofia da história”, de Jacques Maritain, além de muitas outras.

Se a obra literária e cultural do professor Edgar é da maior relevância para Minas e para o Brasil, constatei, mais uma vez, que a sua obra-prima, construída na alegria e no sofrimento, na dor e na esperança, foi a sua própria vida. Aliás, as duas (obra e vida) se complementam na coerência admirável que unia o seu pensamento à sua ação, esta sempre reflexiva. Punha em prática os valores e virtudes em que acreditava. Assim, mestre Edgar foi um homem bom e justo. Alcançou os níveis mais elevados da sabedoria. A justiça foi para ele uma estrela guia na melhor tradição de Aristóteles, de Tomás de Aquino, de Jacques Maritain, da Doutrina Social da Igreja, vale dizer, na melhor tradição fundada por Jesus de Nazaré e vivenciada, ao longo dos séculos, pelos que têm fome e sede de justiça.

Professor Edgar, na sua existência entre nós, foi uma personalidade una e múltipla. Era rigorosamente uno na sua integridade e fidelidade aos princípios que bem ordenaram sua vida desde os tempos de seminário em Diamantina. Pensou e viveu desde então a liberdade, a democracia, os direitos da pessoa humana, a justiça social; a causa dos trabalhadores, dos pobres, dos oprimidos. Sempre se colocou, não simplesmente contra, mas em posição de enfrentamento a todas as formas expressas ou veladas de ditadura ou opressão.

Não se deixou levar pelo canto da sereia, tão sedutor naqueles tempos, do integralismo. O combate ao nazifascismo é a linha unificadora do "Memorial

Doutorando em Filosofia pela Universidad Complutense de Madrid, mestre em Direito Processual pela PUC Minas, graduado em Direito pela UFMG, professor de Introdução ao Estudo de Direito na Faculdade Mineira de Direito da PUC Minas e pesquisador da Escola Legislativa da Assembleia Legislativa de Minas Gerais. Ex-ministro do Desenvolvimento Social e Combate à Fome, ex-deputado federal, ex-vereador e ex-prefeito de Belo Horizonte-MG. Site: patrusananias.com.br. 
de ideias políticas", onde estão os textos por ele publicados em "O Diário", o diário católico, nos anos de 1941 a 1944.

$\mathrm{Na}$ mesma linha, opôs-se à ditadura do Estado Novo; nunca aquiesceu com as ditaduras, pretensamente católicas, de Franco e Salazar.

Defrontou-se com o comunismo no plano devido: crítica vigorosa ao totalitarismo político, crítica ao ateísmo como princípio e razão de Estado, por ser forma paradoxal de negar o caráter laico do próprio Estado e, finalmente, desencanto com as formas de controle do povo, sem falar na manipulação do conhecimento e da informação. Ao contrário da lógica perversa do capitalismo, não condenava o comunismo em sua totalidade, pois reconhecia, com Jacques Maritain, que o marxismo se insere na tradição do iluminismo e, por isso, estava comprometido com o imenso, talvez interminável, esforço de emancipação do gênero humano. E não há como negar que a libertação do ser humano, de todos os seus cativeiros, é uma ideia enraizada na virtude da esperança.

É verdade também que, no contexto da Guerra Fria, considerava a militância anticomunista como uma das metamorfoses do integrismo religioso ou, pura e simplesmente, do fascismo. E denunciava a violência visceral que animava o anticomunismo em seus embates políticos, tornando-o paradoxalmente um stalinismo às avessas.

Íntegro nas suas conviç̧ões e, com base nelas, tomando "sempre a posição de suas ideias", seguindo a orientação de Milton Campos, Edgar, como vimos, foi um homem múltiplo nas suas ações. Em todas elas, manteve uma linha unificadora (as causas pelas quais vivia, pensava e combatia). Edgar foi um pensador, um escritor, um intelectual militante. Demorei a fixar-me neste termo: "militante". Pensei em outros igualmente presentes em sua obra: "apostolado", "testemunho". Militante era-lhe uma palavra, pelo menos, simpática. Ele a emprega ao mencionar o irmão Fausto, "militante estudantil na juventude". Na conferência "Catolicismo e Política", sobre a qual nos ateremos um pouco mais à frente, fala de uma exigência que se endereça de modo especial "ao militante objetivo". Distingue a Igreja militante da Igreja triunfante. Referiu-se a si próprio como "militante político". A partir, sobretudo, de 1964, pós-golpe, a ação política de Edgar leva-o, na radical fidelidade à sua fé religiosa, a estabelecer novas e crescentes relações ecumênicas e seculares. Optei, então, pelo termo "militante".

Retomemos, então, o jornalismo, o qual Edgar exerceu como profissão e missão por mais de dez anos. Vimos algumas diretrizes que o 
nortearam nos anos da Grande Guerra. Enfatizemos um aspecto: a adesão incondicional à causa dos países aliados. Para ele, era uma guerra justa em face do expansionismo bélico do nazismo. Instigante ver um cristão, no sentido mais profundo e evangélico do termo, naquele contexto histórico de gravíssimas ameaças à civilização no que ela sofridamente construiu de melhor ao longo dos séculos, dos milênios, defender a guerra total e a participação do Brasil: "O mundo está empenhado em uma guerra total [...]. A guerra total exige a participação total. E a nossa guerra, a do Brasil, nada tem a ver com uma coisa particular, não é intervenção do Estado Novo, por exemplo, é participação no seu melhor sentido”. Convoca, além dos bravos da Força Expedicionária Brasileira, todo o povo brasileiro a participar da guerra: "Os brasileiros vão à guerra [...] vamos à guerra $[\ldots]$ no momento em que uma nação entra em guerra ao povo competirá fazer a guerra”.

Emerge das páginas do "Memorial", e perpassa toda a sua obra, uma crítica contundente ao capitalismo. Edgar queria ver, sobre os escombros da guerra, emergir uma nova civilização que, liberta de todas as formas de opressão política, se libertasse igualmente da opressão econômica, inclusive do capitalismo de Estado implantado pelo comunismo. Edgar, em perfeita sintonia com as diretrizes mais nítidas e permanentes dos ensinamentos de Jesus, não podia admitir como permanente uma sociedade que fez do capital, do dinheiro, dos bens materiais a sua referência fundamental, acima da própria dignidade da pessoa humana. Não defendia o fim da propriedade privada, antes pelo contrário, como veremos, nem mesmo o fim da livre iniciativa, da economia de mercado. Queria, como muitos de nós, seus discípulos, continuaremos querendo e pelejando, que a propriedade e os negócios estivessem subordinados às exigências superiores do direito à vida, da efetiva aplicação dos direitos humanos, que são hoje os direitos fundamentais da nossa Constituição, do bem comum.

No "Memorial de ideias políticas", fui marcando as referências críticas ao capitalismo. Na décima quinta referência, considerei desnecessário continuar...

Lembremos algumas:

As indústrias de guerra sofrerão uma solução de continuidade súbita, no momento em que vier a paz. Então, o mundo se verá novamente a braços com a questão que o capitalismo suscitou: a questão social. Libertação da necessidade é libertação dos problemas que o capitalismo criou: desemprego, miséria, fome. Libertação da necessidade não será libertação do capitalismo? 
"O verdadeiro e primário fim da produção econômica não é o lucro (capitalismo), mas a satisfação das necessidades do homem (cristianismo social)".

Mestre Edgar, fazendo uma perfeita distinção entre direito de propriedade e direito à propriedade, usa fina ironia para confrontar o sistema que fez do dinheiro a sua referência absoluta:

Atribuiu-se ao capitalismo exatamente um 'crime' que ele não comete: o de ser amigo e defensor da propriedade. Quando não há maior inimigo da propriedade que o capitalismo. É sob o regime capitalista que não há propriedade [...]. A distribuição de propriedade, em regime capitalista, como a distribuição da riqueza, em geral, se caracteriza pelo fato de que, em regime capitalista, não há distribuição, mas absorção [...]

A leveza do humor irônico, que trabalha as possibilidades enigmáticas do paradoxo, alterna-se com a enunciação da palavra profética: "A civilização de hoje é capitalista. É o problema central do mundo moderno - o problema da 'nova ordem', do 'novo mundo', pois o mundo moderno está em liquidação - consiste, nem mais nem menos, em derrubar a ordem capitalista [...]".

Afasta-se, ou é afastado, de "O Diário" em fins de 1944. Veio a exigência de que ele não continuasse como redator-chefe, nem assinasse o suelto de primeira página. "Censura incontrastável", foram suas palavras para definir aquele procedimento ditatorial.

Tornou-se, na sua própria expressão, "repórter político militante" de "O Globo" e "Diário de Notícias". Publicou crônicas, melhor diria pequenos e densos ensaios, no suplemento dominical do saudoso jornal "Correio da Manhā”, a convite do notável ensaísta e crítico literário Álvaro Lins.

A restauração democrática que ocorre com o afastamento do presidente Getúlio Vargas em 1945, e a Constituinte de 1946, trouxe Edgar para o campo da política partidária, para o difícil exercício do poder. Com suas inevitáveis ambivalências a exigir redobrada lucidez. Em 1947, assumiu a chefia da Casa Civil (corresponde hojeà Secretaria de Governo) do governador Milton Campos. Iniciou-se nesse período o tempo em que "passou antes a exercer que a pensar a atividade política". Foi uma experiência que o marcou profundamente. Basta recordar que ouvi dele, e certamente outros amigos também ouviram, que Jacques Maritain, Milton Campos e José Carlos Novais da Mata Machado foram as suas três grandes referências políticas. Personifica em Milton Campos todo o ideário que absorveu de Simone Weil e pôs na epígrafe do seu livro "Direito e coerção": "Esforçar-se, cada 
vez mais, no mundo, para substituir a violência pela não violência eficaz". Para o professor Edgar, "Milton Campos nos ensinou, principalmente, aquilo que viria a inspirar todo o nosso esforço pela libertação: justiça e não violência ativa".

O respeito e a admiração pela pessoa que ele chamou de "grande líder" estendem-se às realizaçôes do seu governo; além dos compromissos republicanos: "Modesto como convém à República e austero como é do gosto dos mineiros", "governo mais da lei do que dos homens, da sensibilidade social: o trabalho é, modernamente, uma das bases da própria organização jurídica, de tal modo que se acentua hoje a fixação desse novo fundamento de nossa organização, ao lado e mesmo acima do conceito elástico de propriedade". Edgar via, além dessas dimensōes, importantes realizaçóes materiais, ao lado dos estudos que fundamentaram o Plano de Recuperação Econômica e Fomento da Produção. Essa leitura positiva do governo Milton Campos, também no aspecto das atividades práticas, encontra sólida confirmação no excelente texto "Milton Campos, a política como moderação", do professor Otávio Soares Dulci, estudo crítico e de apresentação do livro "Memória política de Minas Gerais - Milton Soares Campos", organizado por Fádua Maria de Sousa Gustin e Luciana Murari.

Elegeu-se deputado estadual em 1950 e esteve na Assembleia Legislativa de Minas até 1954. Edgar considerava "catolicismo e política", que se tornou capítulo do livro "O cristão e a cidade", uma síntese do seu trabalho políticolegislativo nesse período. Trata-se de um texto de grande importância para compreender o pensamento e a prática política, sua dimensão de militante reflexivo da política. Edgar trabalha sobre quatro pontos: processo eleitoral, ascensão da classe operária, liberdade de informação, ameaças de clericalismo ou purificação de métodos.

Quando trata do processo eleitoral, coloca-nos diante de questôes importantes. Em alguns pontos seguramente já avançamos, outros continuam a nos desafiar. O texto é de junho de 1958:

Quantas vezes temos ouvido alusões às máquinas eleitorais. A "militança" política ensejou-nos conhecê-las de perto. [...] A influência que se faz sentir, com mais vigor é, sem dúvida, a do dinheiro [...]. É tudo uma rede de compromissos, de transações, de compensações, cuja base, em regra, está no dinheiro, na vantagem pessoal, no lucro individual, em suma, na exploração do povo, dirigida ao que ele tem de mais sagrado, que é o direito de escolha dos seus governantes. 
Mas, assim como hoje, Edgar via os "sinais dos tempos", os sinais da esperança: "Algo de novo, entretanto, começa a impor-se à observação política. É a tomada de consciência da massa proletária urbana, vanguarda da ascensão do operariado à sua idade adulta...”.

Edgar levanta outro tema de forte impacto nos dias atuais. Questiona a propaganda política e o controle das comunicações pelo Estado, principalmente o Estado totalitário. Denuncia o monopólio que "sobre tais sistemas de comunicação exercem governos, partidos, organizações econômicas poderosas".

Há, nesse texto, uma passagem admirável que bem expressa a fecunda relação dialética entre os princípios e as "condições objetivas da realidade" que norteava as suas reflexões e militância política:

Ciência, arte e virtude do bem comum, a política pede conhecimento, pede habilidade ou habilitação técnica, pede prudência [...]. A ação política deve exercer-se num meio determinado, em tempo limitado, em face, às vezes, de circunstâncias imprevistas. Quantos desvios e deformaçōes de mentalidade se explicam (quase se justificariam), pela falta de conhecimento exato de uma dada conjuntura! [...] Impossível atuar politicamente, no Brasil deste e dos próximos dias, sem um conhecimento de sua realidade.

Uma instigante experiência sobre a qual sempre falava com entusiasmo foi o Movimento Político Popular, uma organização suprapartidária fundada no início de 1954, que tinha entre suas finalidades trabalhar pelo aperfeiçoamento das instituições democráticas; pela ascensão dos membros da classe operária, das cidades e dos campos, a condições de vida consentâneas com a dignidade e igualdade da natureza da pessoa humana; instauração de uma economia baseada nas exigências naturais do homem, na dignificação do trabalho e sua implantação, na ordem jurídica, como fonte de direitos superiores aos que decorrem da simples propriedade privada ou da supremacia do capital; recusar qualquer compromisso com o regime capitalista; pleitear junto aos representantes do povo e das autoridades a reforma agrária e uma série de pleitos referente ao acesso à propriedade para os mais pobres, que podemos sintetizar no princípio da função social da propriedade.

A relação dos fundadores do movimento é extremamente elucidativa do seu caráter democrático e popular; nela encontramos professores, funcionários, ambulantes, pedreiros, carpinteiros, advogados, bancário, mecânico, taquígrafo, estudante, engenheiro, químico, dentista, motorista, serrador. 


\section{O presidente do Movimento Político Popular, o dentista Leopoldo}

\section{Garcia Brandão, foi eleito vereador em Belo Horizonte em 1954.}

O início dos anos 1950 é também o começo da carreira (magnífica carreira!) de professor universitário da área do Direito. Lecionara antes nas Faculdades de Filosofia que integrariam depois as universidades Federal e Católica de Minas Gerais. Foi professor de Direito na Faculdade Mineira de Direito da Universidade Católica, da qual foi um dos fundadores, e na Faculdade de Direito da UFMG. A carreira de professor foi acompanhada pela publicação de "Contribuição ao personalismo jurídico", em 1953, livro com o qual concorreu à livre-docência da cadeira de Introdução à Ciência do Direito. Em 1956, obteve a cátedra com a tese "Direito e coerção", que foi publicada no ano seguinte, tornando-se obra de referência. "Elementos de Teoria Geral do Direito", o livro das aulas para os iniciandos do curso de Direito, foi publicado, a primeira vez, em 1972.

Sobre esses livros e o pensamento jurídico do professor Edgar, tratei no meu discurso de posse nesta Academia, quando tive a honra e a responsabilidade de assumir a cadeira que ele ocupou.

O tempo não me permite debruçar-me novamente sobre essas obras, lançando sobre elas (quem sabe?) um novo olhar, 20 anos depois.

Importa registrar, entretanto, que "Contribuição ao personalismo jurídico" é, nas palavras do professor Edgar, "livro entre cujos fundamentos se acha a Declaração Universal dos Direitos do Homem”. Sabemos da importância que teve a declaração na vida intelectual e militante de Edgar. Entre os autores do histórico documento estava Jacques Maritain, que nele se referenciou para escrever "O homem e o Estado". "Contribuição ao personalismo jurídico" foi reeditado em 1999 pela Editora Del Rey, com alentado prefácio da professora Elza Maria Miranda Afonso e texto de apresentação do professor José Edgar Amorim Pereira.

"Direito e coerção", igualmente reeditado pela Unimarco, de São Paulo, em 1999, graças ao empenho do professor e filósofo Marcelo Perine, é a obra que melhor expressa o pensamento jurídico de Edgar Mata-Machado, no plano filosófico. Tese ousada para confrontar o positivismo jurídico: a coerção não é elemento imprescindível da norma jurídica. "A essência do Direito é a liberdade, não a coerção. [...] Diremos, pois, que a nossa tese é mais uma tentativa de situar a coerção, não de a suprimir. E situando-a, ao que nos parece, em seu lugar próprio, a valorizamos e defendemos."

Aqui um registro muito especial: "Direito e coerção" é dedicado a Yedda, "por seu estímulo permanente e sua infatigável cooperação"; noivado em 
1939, casamento em 1940, sete filhos, aos quais acresce Dori, o filho de José Carlos que os avós acolheram e criaram. Casa sempre aberta aos amigos e jovens militantes, tive a alegria de ser um deles. Dona Yedda é solidária coautora em todas as realizações e acolhidas do nosso mestre.

Edgar era um pensador, um sofisticado filósofo do Direito. Mas aqui também se manifesta a sua dimensão de militante. Como em tudo na vida, ele tinha lado: "A posição de suas ideias [...] nunca deixei de manifestar as posiçôes por mim adotadas". Era absolutamente fiel aos princípios espirituais e religiosos, com base nos quais ordenava a sua vida-pensamento e ação. Sabemos que o Direito Natural ou a Lei Natural é um dos pontos mais polêmicos nos estudos da Introdução, da Ciência, da Teoria e da Filosofia do Direito. Afirmava suas convicçôes: "Diremos que um ordenamento jurídico não pode contrariar a lei natural, sob pena de ser destituído de validez e de ter sua eficácia dependente do mero arbítrio da força [...] sustentamos que o Direito deve estar subordinado à Moral".

Ao mesmo tempo em que expressa as suas convicções (como podem e devem fazê-lo os herdeiros de outras tradiçôes!), Edgar jamais perde a dimensão da realidade, ponto de convergência de diferentes visões de mundo. Partindo do conceito de debitum, coisa devida, aquilo que é, desde o início, devido ao ser humano, chega ao Direito Natural,

Cujas conclusões e determinações irão constituir a lei positiva, não à maneira de um decalque de normas engendradas pela pura razão, como imaginavam os jusnaturalistas dos séculos XVII e XVIII, mas nascidas da experiência e das condiçõos concretas da vida em sociedade. Assim é que a própria lei a que Tomás de Aquino chamava "humana" em oposição à natural pode ser o resultado das sucessivas e muitas vezes penosas descobertas do que é devido ao homem, histórica e existencialmente considerado, não mero fruto de uma abstração ou de uma "essência", cujas virtualidades se confinassem nos limites de um céu platônico.

A militância político-partidária ou o exercício da vida pública na perspectiva dos gregos (Aristóteles, na vida intelectual, Péricles, na vida prática), tradição esta bem acolhida e desdobrada pelo melhor da tradição cristã era, para ele, mais do que um desafio, uma realização pessoal. Gostava da política. Nos arquivos sempre escorregadios da memória, consta-me que foi o professor e ex-deputado Cássio Gonçalves, amigo dos mais próximos e constantes do mestre Edgar, que primeiro me chamou a atenção para a sua forte vocação política. Citava com prazer o notável e profético Pe. Lebret: 
Depois da Ação Católica, a tarefa mais nobre é a da ação política [...]. A política está no cume das ciências, das artes e, para empregar uma palavra fora de moda, das virtudes; ela é, cumpre lembrar, a ciência, a arte e a virtude do bem comum [...]. A Política é a mais alta disciplina depois da Teologia; a ambição política é a mais nobre, depois da ambição apostólica [...] apenas os maiores aceitam o pesado fardo do setor político.

Os primeiros anos da década de 1960 vão encontrá-lo como secretário de Estado do governador Magalhães Pinto, ocupando inicialmente as Secretarias da Educação e da Fazenda, firmando-se definitivamente perante a História na Secretaria de Trabalho e Cultura Popular por ele mesmo fundada.

Aí foi encontrá-lo o golpe de 31 de março/1º de abril de 1964 . Viveu, a partir de então, desde os primeiros momentos que levaram ao fim o regime constitucional sob a Carta de 1946, um dos capítulos mais sublimes de sua notável trajetória. Compartilho o que ele me disse em uma de nossas boas, às vezes longas, inesquecíveis conversas que tivemos na sua casa ou na Editora Vega, onde trabalhamos juntos. Disse-me ele que, na primeira conversa com o governador, antecipou a sua saída, dizendo que ele, Edgar, representava no governo a juventude e os trabalhadores. No momento em que suas principais lideranças e militantes eram perseguidos, outro caminho não lhe restava que se posicionar ao lado deles. Posteriormente, quando da visita que recebeu do então governador, reiterou-lhe os motivos que o levavam a afastar-se do governo e acrescentou: "Eu fico com as posiçôes do meu filho", na época aluno do primeiro ano da Faculdade de Direito da UFMG.

Assumiu com bravura o seu lugar no campo dos que se opunham à prepotência e à impostura dos que tomaram pela força o comando do país. Elegeu-se deputado federal em 1966 pelo MDB. Cumpriu, em menos de dois anos, um mandato exemplar. Disse na entrevista à "Revista Vozes" (ano 75, junho/julho 1991, n. 5): "Fui cassado porque exerci o mandato". Pronunciou na Câmara dos Deputados três discursos antológicos, belíssimos na forma, fortes no conteúdo. Esses pronunciamentos históricos integram o "Memorial de ideias políticas" e traduzem a sua admirável coerência:

Pretende-se, antes de mais nada, atrelar o Brasil à civilização ocidental capitalista. De minha parte fico feliz por não ver na elaboração ideológica dos contrarrevolucionários de 1964, alusão à civilização ocidental cristã, pois o abuso do termo "cristão", a identificação entre o cristianismo e a civilização ocidental capitalista chegam a ser algo a que não hesito chamar verdadeiro sacrilégio. 
O Ato Institucional no 5 atingiu-lhe em todas as frentes. Teve o mandato cassado, os direitos políticos suspensos, foi aposentado compulsoriamente como professor da Universidade Federal, impedido de lecionar na Universidade Católica. Em 1973, José Carlos foi assassinado, sob torturas, na prisão.

Edgar não havia completado 56 anos quando o Ato Institucional $n^{\circ}$ 5 cortou-lhe a carreira política e de professor. Daí o título que Alceu Amoroso Lima deu a um de seus dois artigos sobre o "Memorial": "Ave ferida em pleno voo". Ao outro intitulou: "Uma grande voz de Minas".

Conheci Edgar no tempo do "exílio" que a ditadura lhe impôs em sua própria pátria. Julho de 1969 (guardo no coração e na memória). Acompanhei o tempo desta nova e estranha militância (a militância pelo silêncio). Edgar permanecia atento e solidário com as grandes causas do povo brasileiro e da humanidade. Lembro-me bem da sua amorosa adesão à Declaração dos Direitos dos Povos.

A vocação militante e rebelde em face do arbítrio e da violência levou-o ainda, "nos anos de chumbo", a se contrapor aos desmandos da ditadura quando do assassinato de José Carlos. O relato feito à "Revista Vozes" mostra, dia após dia, não obstante o tremendo sofrimento, as enérgicas providências tomadas, ainda que muitas vezes enfrentando a frieza, a indiferença e o escárnio dos algozes do filho. A Anistia, que queríamos ampla, geral e irrestrita para todos os perseguidos e vítimas da ditadura e que não alcançasse os torturadores, veio em 1979. Reintegrado e homenageado pela Universidade Federal de Minas Gerais, profere o discurso que intitulou "Ação popular pela justiça e a liberdade". É uma oração primorosa. Recupera os anos da ditadura que o atingiu tão dura e diretamente. Presta uma afetuosa homenagem a esta Casa. "Não podendo votar nem ser votado, abrem-se para mim as portas da Academia Mineira de Letras, 1973." Mas logo, a 28 de outubro daquele ano, “o grande choque. Meu filho, José Carlos, depois de haver cumprido oito meses de prisão (São Paulo, 1969) por ter participado do Congresso Estudantil de Ibiúna e após ser absolvido em dois outros processos [...] é morto, sob tortura, em Recife".

Cita León Bloy: "Sofrer passa, ter sofrido não passa nunca”. Dá então o testemunho maior, a vivência do mandamento mais radical que Jesus nos propõe: amar os inimigos, perdoar as ofensas, rezar pelos que nos perseguem e caluniam; pelos que torturam e matam os nossos filhos. Edgar perdoou. "A gente aprende a perdoar para ser perdoado." 
Retorna à militância política e ao magistério. Participou da memorável campanha das "Diretas Já". Integrou a Comissão Afonso Arinos, incumbida inicialmente de redigir o projeto da nova Constituição.

Em 1982 aceitou, a meu ver com muita humildade, ser o segundo suplente na chapa para o Senado, liderada pelo senador Itamar Franco. Com a morte do primeiro suplente, Simão da Cunha, assumiu provisoriamente o mandato de senador em 1986, quando Itamar Franco licenciou-se para disputar o governo de Minas. Tornou-se o representante de Minas no Senado em 1990, quando Itamar Franco tornou-se vice-presidente da República. Mais uma vez, ainda que duramente ferido no corpo e na alma (afinal, no limite, para um homem santo é possível perdoar. Mas não há esquecimento!...), dignificou o mandato e honrou as melhores tradições de Minas no Senado Federal. Desenvolveu intensa atividade parlamentar e legislativa, como nos informam os documentos levantados pelo filho, Bernardo Novais da Mata-Machado, que o acompanhou nessa jornada. Foi sua última missão na vida pública.

Quero, antes de encerrar, lembrar duas pessoas notáveis que foram também fortes referências no pensamento e na ação militante do professor Edgar. Maritain foi um mestre no campo filosófico e mesmo político. Alceu Amoroso Lima, grande amigo, foi, sobretudo, influência literária. Com perspicácia e argúcia, resgata a dimensão primeira de Alceu Amoroso Lima em parte obnubilada pela sua intensa militância católica e pela extensão e variedade de sua obra. "Quanto ao Dr. Alceu [...] foi, fundamentalmente, um crítico literário".

Merece registro seu encontro com George Bernanos. O meu amigo, e amigo do professor Edgar, o professor Hugo Pereira do Amaral chama a atenção para dois aspectos. Primeiro, o grande impacto espiritual causado pela personalidade inquieta e ardente de Bernanos, homem profundamente cristão e crítico mordaz de todas as formas de instrumentalização da religião pela política. Sua personalidade arrebatadora não se enquadrava nos estritos limites ditados pela hipocrisia regrada da vida burguesa. $\mathrm{O}$ segundo aspecto é a impressionante atualidade do livro "Diário de um pároco de aldeia", magistralmente traduzido (uma tradução-recriação) pelo professor Edgar. $\mathrm{O}$ general Charles de Gaulle, que, nas palavras de Edgar, falava a linguagem da França e dos franceses, declarou que dois livros o marcaram profundamente: "A condição humana", de André Malraux e o "Diário de um pároco de aldeia”, de George Bernanos. Malraux, por sua vez, expressava nas suas "Antimemórias" o maior apreço e admiração pelo autor de "Sob o sol de Satâ". Emmanuel Mounier, em "A esperança dos desesperados", trata de quatro autores: Sartre, Camus, Malraux e Bernanos. Edgar foi seguramente o 
maior amigo e confidente de Bernanos durante os sete anos em que morou no Brasil. Isso, por si só, atesta a extraordinária fundamentação e sensibilidade cultural do mestre Edgar. Concluo com Edgar citando Bernanos:

Não foi para se americanizar que este país [o Brasil] se empenhou numa terrível aventura [ele falava da Segunda Guerra Mundial], mas ao contrário, para manter o seu lugar no mundo, gostar-se-ia de dizer, o seu lugar na Europa, se a expressão não se prestasse a um mal-entendido, escrevamos, pois simplesmente, o seu lugar na História, na história de uma civilização original, de que Portugal de Salazar é apenas a elegante necrópole, e que revive aqui, cada dia mais vigorosa e mais diferente.

Agora a vez e a voz de Edgar: "Acentue-se, em todo caso, que, nele, Bernanos descreve, sobretudo, o nosso povo do interior, pois nos três anos que já vivera entre nós, conheceu - diz - poucos intelectuais, havendo tido contato, antes, com os nossos camponeses". E Edgar volta a citar Bernanos: "Foram os vossos camponeses que me fizeram compreender os vossos intelectuais - eis a verdade".

No povo humilde dos sertóes do Brasil, Bernanos e Edgar punham a sua fé. Foi essa fé no povo brasileiro, a partir dos pobres, dos camponeses, agricultores, trabalhadores, articulada com a sua fé no mistério cristão, que fizeram de Edgar da Mata-Machado esse símbolo admirável do que há de melhor na nossa gente, na brava gente brasileira. Um país que se exprime numa personalidade como o professor Edgar tem imensas reservas morais e espirituais. Saibamos liberá-las e conduzi-las para grandes realizações e conquistas. Façamos do Brasil um país à imagem e semelhança de Edgar de Godói da Mata-Machado! 